\title{
Differential Expression of Flowering Genes between Rapid- and Slow-Cycling Brassica rapa
}

\author{
Hayong Song ${ }^{1}$, Xiangshu Dong ${ }^{1,3}$, Hankuil $\mathrm{Yi}^{1}$, Ill-Sup Nou ${ }^{2}$, Yoonkang Hur ${ }^{1} *$ \\ ${ }^{1}$ Department of Biological Sciences, College of Biological Science and Biotechnology, Chungnam National University, Daejeon \\ 34134, Korea \\ ${ }^{2}$ Department of Horticulture, Sunchon National University, Suncheon 57922, Korea \\ ${ }^{3}$ School of Agriculture, Yunnan University, Kunming, Yunnan 100044, China
}

\begin{abstract}
Flowering time is a very important agronomic trait in Brassica crops and regulation of the time is one of major factor in the breeding program. To understand the control of flowering time in Brassica rapa, we have carried out Br300K microarray with two contrasting Brassica inbred lines, Rapid Cycling B. rapa (RCBr) as rapid cycling type and B. rapa ssp. pekinensis inbred line Chiifu as slow flowering phenotype. Reproductive process-related genes were specifically expressed in $\mathrm{RCBr}$, whereas environmental stimuli-responsive genes in Chiifu. Flowering stimulating genes, such as BrFT and BrSOC1, were preferentially expressed in RCBr, while flowering repressing genes, such as $B r F L C$ and $B r M A F 4$, expressed in Chiifu. Several paralogues present in $B$. rapa, BrFLCs and $B r C O L$ s, were expressed with paralog-specific pattern depending on flowering phenotypes: i.e., $B r F L C 1$ and $B r F L C 2$, major floral repressors, were expressed in Chiifu, BrFLCL/BrFLC5 in $\mathrm{RCBr}$ and $B r F L C 3$ in both plants. The expression of several flowering repressing genes was gradually decreased in $\mathrm{RCBr}$ growth, but increased in Chiifu growth. However, the expression of genes involved in photoperiodic flowering was no difference between these two plants under LD and SD conditions, indicating photoperiodic pathway is not major factor to distinguish fast vs. slow flowering in B. rapa. The mechanism underlined in the rapid or fast flowering of RCBr would be further elucidated in association with the controlling mechanism of its short life span.
\end{abstract}

Keywords Br300K microarray, Flowering time, RCBr, Chiifu, Photoperiod

\section{INTRODUCTION}

Brassica rapa is an important crop species of the genus Brassica, which is cultivated worldwide and includes a variety of vegetable crops such as Chinese cabbage, Pak-choi, turnip, and turnip green, and oil seed crops including turnip rape and sarson (Gómez-Campo and Prakash 1999). B. rapa ssp. pekinensis (Chinese cabbage) belongs to one of nine subspecies, which is characterized by requirement of long period of cold treatment for flowering. Rapid cycling B. rapa (RCBr), also known as Fast Plant, is a widely used model organism in biology education (Williams and Hill 1986; Musgrave 2000). RCBr was developed by selection of $B$. rapa for several traits, such as short time to flowering, rapid seed maturation, lack of seed dormancy, petite growth habit, and high female fertility
(Williams and Hill 1986). The result is a plant with 10-generations per year. The earliness of flowering is an important trait for crops with higher seed yields (such as oilseed rape), whereas the lateness of flowering is a favourable trait for crops with high leafy head yields (such as Chinese cabbage) (Mao et al. 2014; Wang et al. 2014).

Flowering, a developmental process that transits vegetative stage to reproductive stage, is very important trait in Brassica species. Flowering in Arabidopsis thaliana, a model plant, is controlled by at least five genetically defined regulatory pathways: the photoperiod-dependent, vernalization-dependent, gibberellic acid (GA)-dependent, autonomous promotion, and FRIGIDA (FRI)-dependent pathways (Lee et al. 2000). Flowering time of the Chinese cabbage is largely controlled by vernalization and photoperiod (Kakizaki et al. 2011). Vernalization, exposure to

Received May 5, 2016; Revised May 15, 2016; Accepted May 17, 2016; Published May 31, 2016

*Corresponding author Yoonkang Hur, ykhur@cnu.ac.kr, Tel: +82-42-821-6279, Fax: +82-42-822-9690 
low temperature, rerepresses FLOWERING LOCUS C (FLC) which is a central repressor of flowering (Helliwell et al. 2015). Plants with high FLC activity are late-flowering because FLC directly represses the expression of the floral inducers FLOWERING LOCUS T(FT) and SUPPRESSOR OF OVEREXPRESSION OF CO 1 (SOC1) (Helliwell et al. 2006). Four copies of $F L C$ have been reported in $B$. rapa, and five copies were identified in B. napus (Lin et al. 2005; Kim et al. 2006; 2007). A genetic-genomics approach revealed that $B r F L C 2$ is a major regulator of flowering time in B. rapa (Xiao et al. 2013; 2014). Recently, Li et al. (2016) reported that mutation in $F L C 1$ and $F L C 2$ leading to production of truncated proteins was associated with shortness of flowering time in B. rapa. In photoperiodic flowering pathway, CONSTAS (CO) induces the day-length specific expression of $F T$ in leaves (Putterill et al. 1995; Samach et al. 2000). Both CO and FT are mainly expressed in the vascular tissue of leaves (Takada and Goto 2003).

Although the regulation of flowering genes are important in Brassica breeding, information on $\mathrm{RCBr}$ with respect to gene expression and rapid flowering is still unclear. To get insight on flowering-control mechanism, we have applied Br300K microarray (Dong et al. 2013) using two contrast $B$. rapa inbred lines, $\mathrm{RCBr}$ as rapid cycling B. rapa and B. rapa ssp. pekinesis inbred line Chiifu as slow cycling B. rapa. Differentially expressed genes (DEGs) and major flowering genes were identified and characterized.

\section{MATERIALS AND METHODS}

\section{Plant materials}

Plant materials were rapid cycling Brassica rapa inbred line $(\mathrm{RCBr} 24001)$ as an extremely early-flowering type and B. rapa ssp. pekinensis, inbred line Chiifu as slow or late flowering type. Plants were grown under either long day (LD; 16 hours light/ 8 hours dark) or short day (SD; 8 hours light $/ 16$ hours dark) conditions with $140 \pm 2 \mu \mathrm{l} / \mathrm{m}^{2} / \mathrm{s}$ light intensity at $22^{\circ} \mathrm{C} \pm 5^{\circ} \mathrm{C}$. For microarray, shoots were sampled at both cotyledon stage and five-leaves stage of $\operatorname{RCBr}$ (2 weeks old) and Chiifu (4 weeks old), and stored at $-70^{\circ} \mathrm{C}$ until use. For expression study during $\mathrm{RCBr}$ development, $\mathrm{RCBr}$ and Chiifu (as control) were sampled until $\mathrm{RCBr}$ started flowering. To compare expression of several flowering genes, plants were grown under LD and SD conditions until 21 day after germination (DAG), and sampled at indicated time.

\section{RNA isolation and hybridization to the Br300K microarray GeneChip}

Shoot samples from cotyledon stage and five-leave stage were ground in liquid nitrogen, and equal amounts of powders were pooled. Total RNA was isolated from samples using TRIzol reagent (Invitrogen, Carlsbad, CA, USA), and further purified with a NucleoSpin RNA Clean-up Kit (Macherey-Nagel GmbH\&Co. KG, Düren, Germany). For biological repeats, RNAs were extracted from two independent samples, and subjected to microarray experiment. Microarray experiments and subsequent analyses were performed as described in our previous report (Dong et al. 2013). To obtain insights regarding the putative biological functions and biochemical pathways of DEGs, we carried out enrichment analyses by searching Gene Ontology (GO) (Ashburner et al. 2000), agriGO (Du et al. 2010), and the Kyoto Encyclopedia of Genes and Genomes (Kanehisa et al. 2008).

\section{Reverse transcription polymerase chain reaction (RT-PCR) analysis}

Total RNA was isolated using TRIzol reagent (Invitrogen), and the total RNA $(1 \mu \mathrm{g})$ from each sample was subjected to the first-strand cDNA synthesis using the Ace- $\alpha$ kit with the Oligo(dT) primers (Toyobo, Osaka, Japan). Complementary DNA was diluted 10-fold and $1 \mu \mathrm{l}$ of diluted cDNA was used in a $20-\mu 1$ PCR mixture. RT-PCR primers were listed in Table 1, and primers for BrACT2 (B. rapa Actin 2) used as control are 5'-GAACCGGGTGCTCCTCAGGA-3' (forward) and 5'-ATGGTACCGGAATGGTCAAGGC-3' (reverse). To design paralog specific primer, expressed sequence tag (EST)sequences were subjected to BRAD (http://brassicadb. org/brad/; V1.5), and all sequences were then aligned to figure out polymorphism. A standard PCR was performed with a 5-minute denaturation at $94^{\circ} \mathrm{C}$, followed by 25 
Table 1. List of primers used in qRT-PCR analysis.

\begin{tabular}{|c|c|c|c|c|}
\hline $\mathrm{Br}$ ID $^{\mathrm{z})}$ & Gene & Gene annotation & Forward primer & Reverse primer \\
\hline Bra004503 & $\mathrm{BrCCAl}$ & CIRCADIAN CLOCK-ASSOCIATED 1 & 5'-CTTATGGACCTTCCGGTGAA & 5'-TTCGAGCCACAAGAAGACCT \\
\hline Bra008669 & $\mathrm{BrCO}$ & CONSTANS & 5'-GGCTCCTCAGGAAGTCACTACAA & 5'-GCCATATCCTGTGTCATAGTACATTAGC \\
\hline Bra008668 & BrCOL1-1 & CONSTANS LIKE-1-1 & 5'-GCAACAGACCAACTACCTGACC & 5'-CGAAGGAACAACTCCATATCCTGTGTTG \\
\hline Bra023541 & $\mathrm{BrCOLI-2}$ & CONSTANS LIKE-1-2 & 5'-CAACGGAGGAATTACCTGAAGCC & 5'-TGAAGGAACAATTCCATATCCTGTGTCA \\
\hline Bra001043 & BrCOL2-1 & CONSTANS LIKE-2-1 & 5'-CTGTTGTGCCAGAGTCAACAGAGAG & 5'-TTTGCAAAACGTCCCTTGATCCG \\
\hline Bra021464 & $\operatorname{BrCOL} 2-2$ & CONSTANS LIKE-2-1 & 5'-CGTTAGTGTTGTGCCAGAGTCATCAAG & 5'-CTATCCTCTTTGCGAAACGGCCT \\
\hline Bra032061 & $\mathrm{BrCOL3}$ & CONSTANS LIKE-3 & 5'-ACTTTCCCACACGGATTCAG & 5'-TCGCTTAGCAAAACGTCCTT \\
\hline Bra040020 & BrCOL9-1 & CONSTANS LIKE-9-1 & 5'-GTTATGCAGCACATGCAAACTCACC & 5'-GCTCTCAGCTGGTTGCACTGAG \\
\hline Bra029666 & $\mathrm{BrCOL9-2}$ & CONSTANS LIKE-9-2 & 5'-AGCCTTTAACACCTCTGGAGAGCTA & 5'-ACCGGAGAGCTGCATTGAAGAC \\
\hline Bra001264 & $\mathrm{BrCOL9-3}$ & CONSTANS LIKE-9-3 & 5'-CAGTTCTGCAGCACAAGCAACAA & 5'-GCTCCGTTTTAGAACTCATGAACGAGTC \\
\hline Bra009055 & $B r F L C l$ & FLOWERING LOCUS C $1-1$ & 5'-TCGTCAGTCAAAAGCTTTGGACTGT & 5'-TCGGAGATTTGTCCTGGTGAGACA \\
\hline Bra028599 & $B r F L C 2$ & FLOWERING LOCUS C $1-2$ & 5'-CACACCATGAGCTACTAGAGCTTGTC & 5'-GCAGTCGGAGAGTTACCGGAC \\
\hline Bra006051 & $B r F L C 3$ & FLOWERING LOCUS C $1-3$ & 5'-CACACCATGAGCTACTAGAGCTTGTC & 5'-GCAGTCGGAGAGTTACCGGAC \\
\hline Bra001357 & $B r F L D$ & FLOWERING LOCUS D & 5'-GGAGTGAAGCTTGTGGGAAG & 5'-CACCGGTCCTTTAATCCTGA \\
\hline Bra023965 & BrKNAT5-1 & KNOTTED1-LIKE HOMEOBOX GENE 5-1 & 5'-GCCTGGAGACACAACGTCTGTG & 5'-TCACATAACCGAAGGAGAAACCATGTC \\
\hline Bra011317 & BrKNAT5-2 & KNOTTED1-LIKE HOMEOBOX GENE 5-2 & 5'-AGAGCGGGAGAGATCCTTGC & 5'-GCAAACCGGTTTCTTCAACCAGTTTC \\
\hline Bra024351 & BrMAF4 & MADS AFFECTING FLOWEING 4 & 5'-CGGRAAACTCTATASCTCCTCC & 5'-TTCCGATGACATTGCTCCTTCAC \\
\hline Bra040518 & $B r M B D 9$ & METHYL-CPG-BINDING DOMAIN 19 & 5'-CCTTATTCATTAGCAACTGAAGAAGGC & 5'-AGCAGCCGCTGAAAGAGAAGAC \\
\hline Bra006322 & BrSEPI-l & SEPALLATA $1-1$ & 5'-GCCAGCAAAGGAATCTTCTTGGG & 5'-GTGATGATGCTCGTACGGAACATTC \\
\hline Bra008674 & BrSEPl-2 & SEPALLATA $1-2$ & 5'-CCTCTGAATTCAAAGGAGTTAGAGCAGA & 5'-CACCAATCATATCATCCAGCTTCATAGC \\
\hline Bra021470 & BrSEPl-3 & SEPALLATA $1-3$ & 5'-CTTGGAGAGGACCTTGGACCC & 5'-CTTCATTGACAAAGCACGATTGGCG \\
\hline Bra039170 & BrSEPl-4 & SEPALLATA $1-4$ & 5'-GCGTCAACTAGACGGCTCTCTG & 5'-GTGATGATGCTCGTACGGAACATTC \\
\hline Bra037544 & BrVRNI & REDUCED VERNALIZATION RESPONSE 1 & 5'-CCGTTCAAAGTTCTACGAGAGTGC & 5'-TCAGACGTACTCGTTGACTCGAWA \\
\hline Bra021078 & $B r V R N 2$ & REDUCED VERNALIZATION RESPONSE 2 & 5'-CAAGAAAGTTATCTGCTGAGCGATC & 5'-TATTGCAGTTGTTGATGGTGGC \\
\hline
\end{tabular}

${ }^{\mathrm{z})}$ BRAD ID number identified by BlastN with expressed sequence tag sequence at http://brassicadb.org/brad/. qRT-PCR: quantitative reverse transcription polymerase chain reaction.

cycles of $94^{\circ} \mathrm{C}$ for 30 seconds, $55^{\circ} \mathrm{C}$ for 30 seconds, and $72^{\circ} \mathrm{C}$ for 90 seconds. PCR products were analyzed following electrophoresis through a $1.2 \%$ agarose gel.

\section{RESULTS}

\section{Overall microarray}

Among 47,553 EST clones deposited on Br300K microarray, 40,047 (84\%) showed over 500 in probe intensity (PI), which means their transcripts could be detected by regular RT-PCR (Supplementary Table 1). In addition, 8,542 clones were not annotated with Arabidopsis gene locus (18\% and expressed as 'no_hit_found', HNF). Estimated number of genes in $B$. rapa ssp. pekinensis inbred line Chiifu and RCBr will be 44,710: 41,173 from BRAD (http://brassicadb.org/brad/; V1.5) (Wang et al. 2011), and 3,537 novel genes recently identified by deep RNA-Seq (Devisetty et al. 2014). Our microarray included more number of EST clones than the estimated numbers, but actual coverage of unigenes will be below $80 \%$ due to overlapped EST clones.

\section{Differentially or specifically expressed genes}

Genes showing $\mathrm{RCBr}$-specific expression were defined as those genes with PI values greater than 1,000 in $\mathrm{RCBr}$ but less than 500 in Chiifu (Supplementary Table 2). Chiifu-specific expression genes were selected with same strategy as RCBr (Supplementary Table 3). RCBr- and Chiifu-specifically expressed genes were 541 and 1,037, respectively. Among them, 178 (33\%) and 446 (43\%) genes from $\mathrm{RCBr}$ and Chiifu, respectively, were NHF: i.e., no Arabidopsis counterpart to be present. These NHFs will be Brassica specific genes (or ophan genes). Only 363 and 591 genes from $\mathrm{RCBr}$ and Chiifu, respectively, were annotated with Arabidopsis genome data. RCBr-specific genes included many flowering-stimulating genes and transposable elements. On the other hand, Chiifu-specific genes included several floral repressor genes, such as FLC and $M A F 4$.

To obtain insights regarding the putative biological functions and biochemical pathways of DEGs, we carried 
out GO enrichment analyses by searching agriGO (Du et al. 2010) using RCBr- (Supplementary Table 2) or Chiifuinduced genes (Supplementary Table 3). With the threshold value ( $P$-value) below $0.05,51$ and $159 \mathrm{GO}$ items were significantly enriched by the $\mathrm{RcBr}$ - and Chiifu-induced genes, respectively (Fig. 1). GO items related reproductive processes were only significantly represented by $\mathrm{RCBr}$ induced genes, such as gametophyte development, flower development and cell differentiation. On the other hand, GO items related to stress response or environment stimulus were only significantly represented by Chiifuinduced genes. There are $27 \mathrm{GO}$ Cellular component items were significantly represented in Chiifu-induced genes, and most of them related membrane structure, no such items were represented in $\mathrm{RCBr}$-induced genes.

\section{Transcription factors (TFs)}

Since TFs play roles as a master controller for plant growth and development, differentially expressed TF genes were analyzed (Table 2). In this analysis, we omitted TFs classified as flowering genes and then summarized as three catagoris; highly expressed-top 20 genes in both $\mathrm{RCBr}$ and Chiifu, RCBr-specific and Chiifu-specific genes. Ethylene-responsive TF RAP2-4 (RAP2.4) was the most highly expressed TF in both plants with over 40,000 in PI values. Genes expressed over two fold in $\mathrm{RCBr}$ and Chiifu were 19 and 20, respectively; representative genes were CAULIFLOWER (CAL) and SHINE2 (SHN2) for $\mathrm{RCBr}$, and KNOTTED1-LIKE HOMEOBOX GENE 5 (KNAT5) and CURLY LEAF (CLF) for Chiifu.

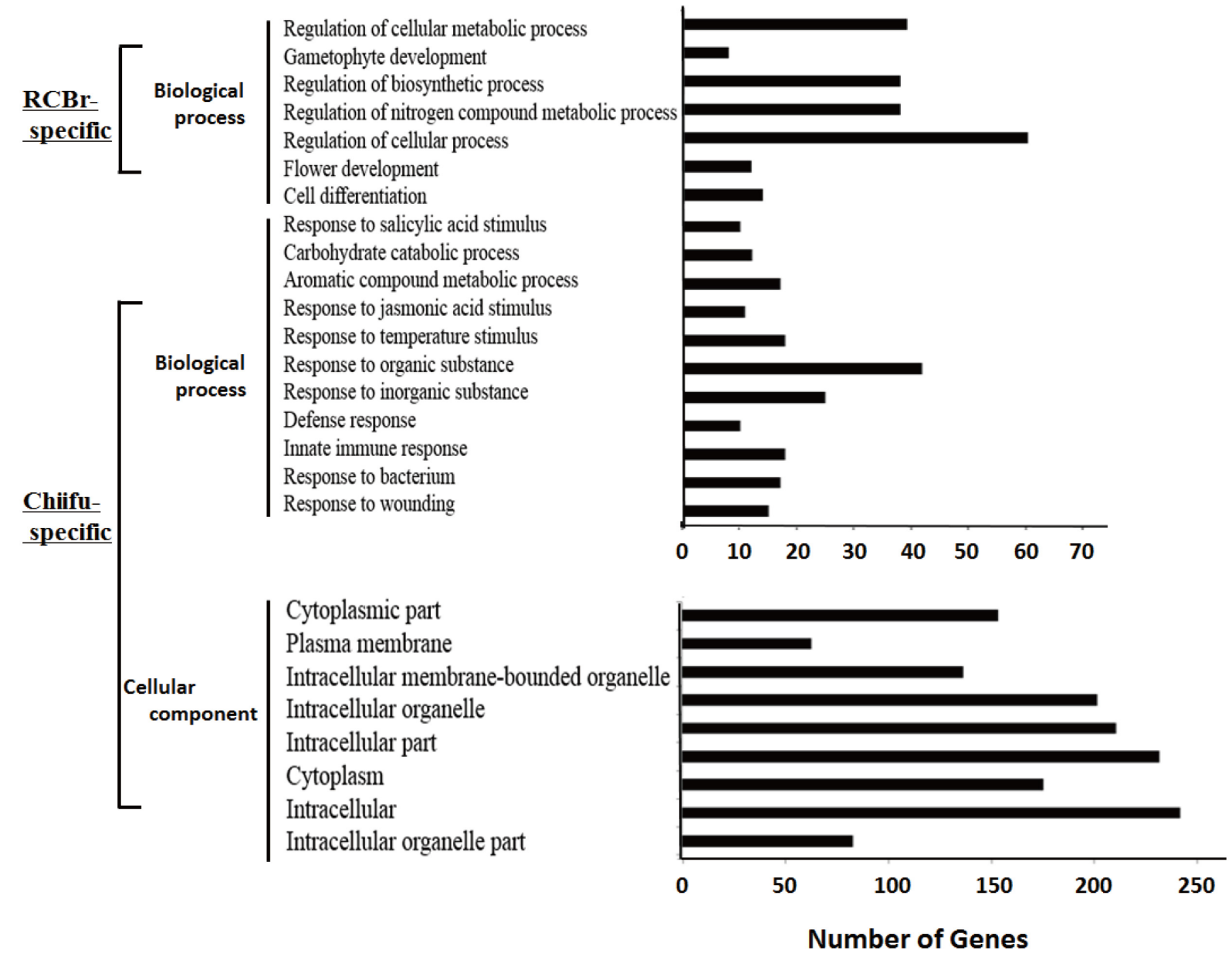

Fig. 1. Functional categorization of differentially expressed genes between $\mathrm{RCBr}$ and Chiifu based on gene ontology dirstribution. 
Table 2. Transcription factors whose expressions levels were top 20 in both RCBr and Chiifu, and over two-fold in RCBr or Chiifu.

\begin{tabular}{|c|c|c|c|c|c|c|c|}
\hline \multirow{2}{*}{ Classification } & \multirow{2}{*}{ At_Locus } & \multirow{2}{*}{ Gene annotation } & \multirow{2}{*}{ Br_SEQ_ID } & \multicolumn{2}{|c|}{ Probe intensity } & \multicolumn{2}{|c|}{ Fold change } \\
\hline & & & & $\mathrm{RCBr}$ & Chiifu & $\mathrm{R} / \mathrm{C}^{2)}$ & $\mathrm{C} / \mathrm{R}$ \\
\hline \multirow{20}{*}{$\begin{array}{l}\text { Top } 20 \text { in both } \\
\mathrm{RCBr} \text { and } \\
\text { Chiifu }\end{array}$} & AT1G78080 & RAP2.4 (Ethylene-responsive transcription factor RAP2 4) & Brapa_ESTC021276 & 40264 & 40257 & 1.0 & 1.0 \\
\hline & AT3G54810 & BME3/BME3-ZF (BLUE MICROPLYLAR END3) & Brapa_ESTC043727 & 38658 & 39227 & 1.0 & 1.0 \\
\hline & AT3G15210 & ATERF4/ERF4 (ETHYLENE RESPONSIVE ELEMENT BINDING FACTOR 4) & Brapa_ESTC031149 & 38808 & 38636 & 1.0 & 1.0 \\
\hline & AT1G65440 & GTB1 (GLOBAL transcription factor GROUP B1) & Brapa_ESTC034584 & 33003 & 38201 & 0.9 & 1.2 \\
\hline & AT5G59820 & ZAT12 | RHL41 (RESPONSIVE TO HIGH LIGHT 41) & Brapa_ESTC009473 & 34297 & 37970 & 0.9 & 1.1 \\
\hline & AT1G28370 & ATERF11/ERF11 (ERF domain protein 11) & Brapa_ESTC031565 & 37200 & 36359 & 1.0 & 1.0 \\
\hline & AT1G20696 & HMGB3 (HIGH MOBILITY GROUP B 3) & Brapa_ESTC008254 & 34477 & 35904 & 1.0 & 1.0 \\
\hline & & & Brapa_ESTC000857 & 35055 & 30406 & 1.2 & 0.9 \\
\hline & AT1G80840 & WRKY40 (WRKY DNA-binding protein 40) & Brapa_ESTC014413 & 35089 & 33203 & 1.1 & 0.9 \\
\hline & & & Brapa_ESTC023350 & 33999 & 31364 & 1.1 & 0.9 \\
\hline & AT4G34410 & AP2 domain-containing transcription factor, putative & Brapa_ESTC044996 & 30380 & 32899 & 0.9 & 1.1 \\
\hline & AT1G50600 & SCL5 (Scarecrow-like protein 5) & Brapa_ESTC017171 & 30623 & 32226 & 1.0 & 1.1 \\
\hline & AT1G27730 & ZAT10 | STZ (SALT TOLERANCE ZINC FINGER) & Brapa_ESTC040097 & 42218 & 32094 & 1.3 & 0.8 \\
\hline & AT4G10710 & SPT16 (GLOBAL transcription factor C) & Brapa_ESTC033093 & 29057 & 31334 & 0.9 & 1.1 \\
\hline & AT2G37630 & MYB91 | AS1 (ASYMMETRIC LEAVES 1) & Brapa_ESTC001152 & 31517 & 30950 & 1.0 & 1.0 \\
\hline & AT5G52660 & MYB family transcription factor & Brapa_ESTC046861 & 38201 & 29175 & 1.3 & 0.8 \\
\hline & AT1G12610 & DDF1 (DWARF AND DELAYED FLOWERING 1) & Brapa_ESTC039504 & 30466 & 29121 & 1.0 & 1.0 \\
\hline & AT5G48150 & PAT1 (PHYTOCHROME A SIGNAL TRANSDUCTION 1) & Brapa_ESTC021790 & 38241 & 28474 & 1.3 & 0.7 \\
\hline & AT3G50060 & MYB family transcription factor & Brapa_ESTC024817 & 38077 & 28352 & 1.3 & 0.7 \\
\hline & AT4G31550 & WRKY11 (WRKY DNA-binding protein 11) & Brapa_ESTC044727 & 29815 & 28222 & 1.1 & 0.9 \\
\hline \multirow[t]{20}{*}{$\mathrm{RCBr}$ specific } & AT5G21120 & EIL2 (ETHYLENE-INSENSITIVE3-LIKE 2) & Brapa_ESTC037616 & 1460 & 116 & 12.6 & . \\
\hline & AT2G45680 & TCP family transcription factor, putative & Brapa_ESTC042103 & 3852 & 377 & 10.2 & . \\
\hline & AT1G26310 & CAL (CAULIFLOWER) & Brapa_ESTC017036 & 2570 & 287 & 9.0 & . \\
\hline & AT1G15050 & IAA34 (indoleacetic acid-induced protein 34) & Brapa_ESTC033550 & 2023 & 250 & 8.1 & . \\
\hline & AT1G76890 & GT2 (GT2) & Brapa_ESTC003989 & 1178 & 199 & 5.9 & . \\
\hline & AT5G25390 & SHN2 (Ethylene-responsive transcription factor SHINE3) & Brapa_ESTC032163 & 1763 & 307 & 5.7 & . \\
\hline & AT1G73830 & BEE3 (BR-ENHANCED EXPRESSION 3) & Brapa_ESTC019151 & 2796 & 496 & 5.6 & . \\
\hline & AT5G22290 & ANAC089 (Arabidopsis NAC domain containing protein 89) & Brapa_ESTC021310 & 1579 & 281 & 5.6 & . \\
\hline & & & Brapa_ESTC034036 & 1104 & 301 & 3.7 & . \\
\hline & AT1G69560 & MYB105 (myb domain protein 105) & Brapa_ESTC040454 & 1409 & 277 & 5.1 & . \\
\hline & AT5G15310 & AtMYB16 (myb domain protein 16 ) & Brapa_ESTC025442 & 1817 & 419 & 4.3 & . \\
\hline & AT1G20530 & Unknown (similar to bzip-related transcription factor -like) & Brapa_ESTC000221 & 1921 & 497 & 3.9 & . \\
\hline & AT5G60890 & AtMYB34 | ATR1 (ALTERED TRYPTOPHAN REGULATION) & Brapa_ESTC026773 & 1226 & 326 & 3.8 & . \\
\hline & AT1G17590 & CCAAT-binding transcription factor (CBF-B/NF-YA) family protein & Brapa_ESTC003250 & 1089 & 302 & 3.6 & . \\
\hline & AT4G33280 & AP2/B3-like transcription factor & Brapa_ESTC044866 & 1607 & 480 & 3.3 & . \\
\hline & AT2G03060 & Similar to AGL102 & Brapa_ESTC019197 & 1325 & 401 & 3.3 & . \\
\hline & AT3G12720 & AtMYB67/AtY53 (myb domain protein 67) & Brapa_ESTC042873 & 1358 & 467 & 2.9 & . \\
\hline & AT5G06839 & bZIP family transcription factor & Brapa_ESTC045391 & 1162 & 455 & 2.6 & . \\
\hline & AT4G32280 & IAA29 (indoleacetic acid-induced protein 29) & Brapa_ESTC035154 & 1126 & 472 & 2.4 & . \\
\hline & AT1G15360 & SHN1/WIN1 (SHINE1/WAX INDUCER 1) & Brapa_ESTC017040 & 1064 & 464 & 2.3 & . \\
\hline \multirow[t]{21}{*}{ Chiifu specific } & AT4G32040 & KNAT5 (KNOTTED1-LIKE HOMEOBOX GENE 5) & Brapa_ESTC025634 & 44 & 18085 & . & 413.2 \\
\hline & AT5G51190 & AP2 domain-containing transcription factor, putative & Brapa_ESTC013139 & 145 & 12449 & . & 85.7 \\
\hline & AT4G01550 & ANAC069 (Arabidopsis NAC domain containing protein 69) & Brapa_ESTC007789 & 95 & 7576 & . & 80.0 \\
\hline & AT3G50260 & CEJ1 (COOPERATIVELY REGULATED BY ETHYLENE AND JASMONATE 1) & Brapa_ESTC001959 & 17 & 1102 & . & 66.0 \\
\hline & AT5G60890 & AtMYB34 | ATR1 (ALTERED TRYPTOPHAN REGULATION) & Brapa_ESTC009043 & 408 & 22870 & . & 56.1 \\
\hline & AT2G22430 & ATHB6 (ARABIDOPSIS THALIANA HOMEOBOX PROTEIN 6) & Brapa_ESTC004579 & 323 & 13848 & . & 42.9 \\
\hline & AT2G46970 & PIL1 (PHYTOCHROME INTERACTING FACTOR 3-LIKE 1) & Brapa_ESTC042137 & 108 & 3570 & . & 33.1 \\
\hline & AT2G42780 & similar to Os08g0169600 & Brapa_ESTC050862 & 49 & 1577 & . & 32.1 \\
\hline & AT1G49950 & ATTRB1/TRB1 (TELOMERE REPEAT BINDING FACTOR 1) & Brapa_ESTC051029 & 270 & 4988 & . & 18.5 \\
\hline & AT4G12020 & MAPKKK11 | WRKY19 (WRKY DNA-binding protein 19) & Brapa_ESTC030987 & 149 & 2540 & . & 17.1 \\
\hline & & & Brapa_ESTC037364 & 397 & 5334 & . & 13.4 \\
\hline & AT5G59820 & ZAT12 | RHL41 (RESPONSIVE TO HIGH LIGHT 41) & Brapa_ESTC006145 & 106 & 1379 & . & 13.0 \\
\hline & AT4G31800 & WRKY18 (WRKY DNA-binding protein 18) & Brapa_ESTC001172 & 320 & 3971 & . & 12.4 \\
\hline & AT3G27810 & ATMYB21 (MYB DOMAIN PROTEIN 21) & Brapa_ESTC008010 & 445 & 4910 & . & 11.0 \\
\hline & AT3G61150 & HDG1 (HOMEODOMAIN GLABROUS1) & Brapa_ESTC022251 & 201 & 1813 & . & 9.0 \\
\hline & AT3G28920 & ATHB34 (ARABIDOPSIS THALIANA HOMEOBOX PROTEIN 34) & Brapa_ESTC051903 & 418 & 3716 & . & 8.9 \\
\hline & AT3G11100 & Transcription factor & Brapa_ESTC005968 & 361 & 2986 & . & 8.3 \\
\hline & AT2G23380 & CLF (CURLY LEAF) & Brapa_ESTC048306 & 138 & 1075 & . & 7.8 \\
\hline & AT1G71030 & ATMYBL2 (Arabidopsis myb-like 2) & Brapa_ESTC021435 & 249 & 1760 & . & 7.1 \\
\hline & AT5G16820 & HSFA1B | HSF3 (HEAT SHOCK FACTOR 3) & Brapa_ESTC036030 & 481 & 1465 & . & 3.0 \\
\hline & AT5G61590 & AP2 domain-containing transcription factor family protein & Brapa_ESTC021781 & 465 & 1249 & . & 2.7 \\
\hline
\end{tabular}

${ }^{\mathrm{z})} \mathrm{R} / \mathrm{C}$ and $\mathrm{C} / \mathrm{R}$ indicate the expression ratio in $\mathrm{RCBr}$ over Chiifu and Chiifu over $\mathrm{RCBr}$, respectively. Flowering-related $\mathrm{TF}$ genes were omitted in this Table. 


\section{Flowering genes}

Genes listed in Table 3 were selected from 196 flowering-related genes on Br300K microarray: 26,9 and 23 genes for up-regulated in $\mathrm{RCBr}$, in Chiifu and both, respectively. Genes (26 genes) up-regulated in $\mathrm{RCBr}$ included most flowering-promoting genes, such as $F T$ and
SOC1. On the other hand, genes (9) up-regulated in Chiifu included floral repressors, such as FLC and MAF4. Twenty-three genes were highly expressed in both $\mathrm{RCBr}$ and Chiifu, which included DWARF AND DELAYED FLOWERING 1 (DDFI) and EARLY FLOWERING 3 (ELF3).

Interestingly, expression of several flowering genes

Table 3. Flowering-related genes which were selected from 196 flowering genes on $\mathrm{Br} 300 \mathrm{~K}$ microarray.

\begin{tabular}{|c|c|c|c|c|c|c|c|}
\hline \multirow{2}{*}{ Classification } & \multirow{2}{*}{ At_Locus } & \multirow{2}{*}{ Gene annotation } & \multirow{2}{*}{ Br_SEQ_ID } & \multicolumn{2}{|c|}{ Probe intensity } & \multicolumn{2}{|c|}{ Fold change } \\
\hline & & & & $\mathrm{RCBr}$ & Chiifu & $\mathrm{R} / \mathrm{C}^{\mathrm{z})}$ & $\mathrm{C} / \mathrm{R}$ \\
\hline \multirow{50}{*}{$\begin{array}{l}\text { Up-regulated genes } \\
\text { in } \mathrm{RCBr}\end{array}$} & AT5G20240 & PI (PISTILLATA) & Brapa_ESTC028268 & 4123 & 43 & 95.0 & . \\
\hline & & & Brapa_ESTC008132 & 6436 & 365 & 17.7 & . \\
\hline & & & Brapa_ESTC034308 & 4875 & 799 & 6.1 & . \\
\hline & & & Brapa_ESTC048371 & 872 & 163 & 5.3 & . \\
\hline & & & Brapa_ESTC019275 & 3390 & 359 & 9.4 & . \\
\hline & & & Brapa_ESTC048372 & 3473 & 963 & 3.6 & . \\
\hline & AT5G15800 & SEP1 (SEPALLATA1)/AGL2 & Brapa_ESTC025908 & 1629 & 32 & 50.6 & . \\
\hline & & & Brapa_ESTC011597 & 2267 & 94 & 24.2 & . \\
\hline & & & Brapa_ESTC045715 & 7932 & 402 & 19.7 & . \\
\hline & AT1G69120 & AP1 (APETALA1)/AGL4 & Brapa_ESTC040402 & 8412 & 267 & 31.5 & . \\
\hline & & & Brapa_ESTC017264 & 4988 & 242 & 20.6 & . \\
\hline & & & Brapa_ESTC010543 & 527 & 26 & 20.2 & . \\
\hline & & & Brapa_ESTC008651 & 5851 & 313 & 18.7 & . \\
\hline & AT3G02310 & SEP2 (SEPALLATA2) & Brapa_ESTC008039 & 5018 & 200 & 25.0 & . \\
\hline & & & Brapa_ESTC005886 & 1654 & 69 & 24.0 & . \\
\hline & & & Brapa_ESTC031079 & 4813 & 254 & 19.0 & . \\
\hline & & & Brapa_ESTC049045 & 1242 & 197 & 6.3 & . \\
\hline & AT3G54340 & AP3 (APETALA 3) & Brapa_ESTC010485 & 2902 & 138 & 21.0 & . \\
\hline & & & Brapa_ESTC007881 & 6834 & 1754 & 3.9 & . \\
\hline & AT4G18960 & AG (AGAMOUS) & Brapa_ESTC008198 & 1927 & 93 & 20.6 & . \\
\hline & & & Brapa_ESTC018123 & 2371 & 253 & 9.4 & . \\
\hline & AT1G24260 & SEP3 (SEPALLATA3)/AGL9 & Brapa_ESTC010831 & 8934 & 615 & 14.5 & . \\
\hline & AT2G45650 & AGL6 (AGAMOUS LIKE-6) & Brapa_ESTC018131 & 2547 & 932 & 2.7 & . \\
\hline & AT1G26310 & CAL (CAULIFLOWER)/AGL10 & Brapa_ESTC010942 & 1086 & 112 & 9.7 & . \\
\hline & AT1G65480 & FT (FLOWERING LOCUS T) & Brapa_ESTC017036 & 2570 & 287 & 9.0 & . \\
\hline & & & Brapa_ESTC034579 & 1985 & 278 & 7.1 & . \\
\hline & AT3G07650 & COL9 (CONSTANS-LIKE 9) & Brapa_ESTC019941 & 2432 & 462 & 5.3 & . \\
\hline & & & Brapa_ESTC027877 & 5149 & 819 & 6.3 & . \\
\hline & AT2G45660 & SOC1/AGL20 (AGAMOUS-LIKE 20)(SOC1-2, SOC1-1, SOC1-3) & Brapa_ESTC051650 & 3495 & 1501 & 2.3 & . \\
\hline & & & Brapa_ESTC011095 & 14204 & 3600 & 3.9 & . \\
\hline & & & Brapa_ESTC018989 & 10579 & 3022 & 3.5 & . \\
\hline & & & Brapa_ESTC019044 & 9961 & 3960 & 2.5 & . \\
\hline & AT5G60910 & FUL/AGL8 (AGAMOUS-LIKE 8) & Brapa_ESTC017129 & 22280 & 5691 & 3.9 & . \\
\hline & AT5G24860 & FPF1 (FLOWERING PROMOTING FACTOR 1) & Brapa_ESTC018052 & 4399 & 1195 & 3.7 & . \\
\hline & & & Brapa_ESTC029975 & 2502 & 1078 & 2.3 & . \\
\hline & AT5G62165 & AGL42 (AGAMOUS LIKE 42) & Brapa_ESTC008221 & 3953 & 1108 & 3.6 & . \\
\hline & AT5G03840 & TFL1 (TERMINAL FLOWER 1) & Brapa_ESTC045284 & 898 & 253 & 3.5 & . \\
\hline & AT2G03060 & Similar to AGL102 & Brapa_ESTC019197 & 1325 & 401 & 3.3 & . \\
\hline & AT3G21320 & Similar to ELF3 (EARLY FLOWERING 3) & Brapa_ESTC043198 & 4038 & 1494 & 2.7 & . \\
\hline & & & Brapa_ESTC023599 & 3673 & 1782 & 2.1 & . \\
\hline & AT2G43010 & PIF4 (PHYTOCHROME INTERACTING FACTOR 4) & Brapa_ESTC012017 & 749 & 288 & 2.6 & . \\
\hline & & & Brapa_ESTC018786 & 4340 & 1879 & 2.3 & . \\
\hline & AT2G45830 & DTA2 (DOWNSTREAM TARGET OF AGL15 2) & Brapa_ESTC034818 & 9026 & 3696 & 2.4 & . \\
\hline & AT5G15850 & COL1 (CONSTANS-LIKE 1) & Brapa_ESTC020072 & 2427 & 1002 & 2.4 & . \\
\hline & AT3G59060 & PIF5/ PIL6 (PHYTOCHROME-INTERACTING FACTOR 5) & Brapa_ESTC019071 & 5260 & 2182 & 2.4 & . \\
\hline & & & Brapa_ESTC033456 & 1381 & 590 & 2.3 & . \\
\hline & AT1G71692 & AGL12 (AGAMOUS-LIKE 12) & Brapa_ESTC027067 & 1108 & 485 & 2.3 & . \\
\hline & AT5G10140 & FLC (FLOWERING LOCUS C)/AGL25(FLCL/FLC5) & Brapa_ESTC017216 & 8885 & 4014 & 2.2 & . \\
\hline & AT5G13790 & AGL15 (AGAMOUS-LIKE 15) & Brapa_ESTC010865 & 5636 & 2491 & 2.3 & . \\
\hline & AT2G33350 & Similar to zinc finger CONSTANS-related & Brapa_ESTC041607 & 1624 & 809 & 2.0 & . \\
\hline
\end{tabular}

\footnotetext{
${ }^{\mathrm{z})} \mathrm{R} / \mathrm{C}$ and $\mathrm{C} / \mathrm{R}$ indicate the expression ratio in $\mathrm{RCBr}$ over Chiifu and Chiifu over $\mathrm{RCBr}$, respectively.
} 
Table 3. Continued.

\begin{tabular}{|c|c|c|c|c|c|c|c|}
\hline \multirow{2}{*}{ Classification } & \multirow{2}{*}{ At_Locus } & \multirow{2}{*}{ Gene annotation } & \multirow{2}{*}{ Br_SEQ_ID } & \multicolumn{2}{|c|}{ Probe intensity } & \multicolumn{2}{|c|}{ Fold change } \\
\hline & & & & $\mathrm{RCBr}$ & Chiifu & $\mathrm{R} / \mathrm{C}^{\mathrm{z})}$ & $\mathrm{C} / \mathrm{R}$ \\
\hline \multirow{14}{*}{$\begin{array}{l}\text { Up-regulated genes } \\
\text { in Chiifu }\end{array}$} & AT5G10140 & FLC (FLOWERING LOCUS C)/AGL25(FLC1, FLC2) & Brapa_ESTC016533 & 53 & 1504 & . & 28.3 \\
\hline & & & Brapa_ESTC012276 & 6738 & 13305 & . & 2.0 \\
\hline & AT5G65070 & FCL4/MAF4 (MADS AFFECTING FLOWERING 4) & Brapa_ESTC013135 & 393 & 8499 & . & 21.6 \\
\hline & & & Brapa_ESTC046597 & 986 & 4411 & . & 4.5 \\
\hline & & & Brapa_ESTC013362 & 3209 & 11579 & . & 3.6 \\
\hline & & & Brapa_ESTC046600 & 300 & 1051 & . & 3.5 \\
\hline & & & Brapa_ESTC046598 & 3151 & 9784 & . & 3.1 \\
\hline & AT1G31140 & AGL63 (AGAMOUS-LIKE 63) & Brapa_ESTC040293 & 206 & 2363 & . & 11.5 \\
\hline & AT5G04240 & ELF6 (EARLY FLOWERING 6) & Brapa_ESTC020902 & 368 & 1517 & . & 4.1 \\
\hline & AT5G13790 & AGL15 (AGAMOUS-LIKE 15) & Brapa_ESTC020193 & 1290 & 4174 & . & 3.2 \\
\hline & AT1G30260 & AGL79 (AGAMOUS-LIKE 79) & Brapa_ESTC014642 & 276 & 776 & . & 2.8 \\
\hline & AT1G77080 & AGL27/MAF1 (MADS AFFECTING FLOWERING 1) & Brapa_ESTC022419 & 1327 & 3363 & . & 2.5 \\
\hline & AT1G09530 & PIF3 (PHYTOCHROME INTERACTING FACTOR 3) & Brapa_ESTC026673 & 2332 & 5556 & . & 2.4 \\
\hline & AT3G57390 & AGL18 (AGAMOUS-LIKE 18) & Brapa_ESTC021222 & 2876 & 5626 & . & 2.0 \\
\hline \multirow{49}{*}{$\begin{array}{l}\text { Highly expressed } \\
\text { genes in both } \\
\mathrm{RCBr} \text { and Chiifu }\end{array}$} & AT1G12610 & DDF1 (DWARF AND DELAYED FLOWERING 1) & Brapa_ESTC039504 & 30466 & 29121 & 1.0 & 1.0 \\
\hline & & & Brapa_ESTC002858 & 19586 & 15570 & 1.3 & 0.8 \\
\hline & AT2G25930 & ELF3 (EARLY FLOWERING 3) & Brapa_ESTC041284 & 26959 & 22606 & 1.2 & 0.8 \\
\hline & & & Brapa_ESTC041298 & 22936 & 16177 & 1.4 & 0.7 \\
\hline & & & Brapa_ESTC015252 & 19828 & 20034 & 1.0 & 1.0 \\
\hline & AT1G25540 & PFT1 (PHYTOCHROME AND FLOWERING TIME 1) & Brapa_ESTC047777 & 23968 & 21573 & 1.1 & 0.9 \\
\hline & AT2G22540 & AGL22/SVP (SHORT VEGETATIVE PHASE) & Brapa_ESTC014320 & 23538 & 18005 & 1.3 & 0.8 \\
\hline & & & Brapa_ESTC050176 & 8869 & 9304 & 1.0 & 1.0 \\
\hline & & & Brapa_ESTC041116 & 18874 & 17799 & 1.1 & 0.9 \\
\hline & AT3G04610 & FLK (FLOWERING LOCUS KH DOMAIN) & Brapa_ESTC042608 & 21959 & 17640 & 1.2 & 0.8 \\
\hline & AT5G62640.2 & ELF5 (EARLY FLOWERING 5) & Brapa_ESTC001982 & 19200 & 13055 & 1.5 & 0.7 \\
\hline & AT2G24790.1 & COL3 (CONSTANS-LIKE 3) & Brapa_ESTC011117 & 19001 & 27161 & 0.7 & 1.4 \\
\hline & & & Brapa_ESTC014037 & 15458 & 24927 & 0.6 & 1.6 \\
\hline & & & Brapa_ESTC027269 & 13996 & 19872 & 0.7 & 1.4 \\
\hline & AT5G10140 & FLC (FLOWERING LOCUS C)/AGL25 (FLC3) & Brapa_ESTC013303 & 17486 & 16533 & 1.1 & 0.9 \\
\hline & & & Brapa_ESTC021830 & 13579 & 14983 & 0.9 & 1.1 \\
\hline & AT4G24540 & AGL24 (AGAMOUS-LIKE 24) & Brapa_ESTC036920 & 17200 & 17618 & 1.0 & 1.0 \\
\hline & & & Brapa_ESTC019065 & 14515 & 13686 & 1.1 & 0.9 \\
\hline & AT1G77300 & EFS (EARLY FLOWERING IN SHORT DAYS) & Brapa_ESTC040684 & 17197 & 13552 & 1.3 & 0.8 \\
\hline & AT4G22950 & AGL19 (AGAMOUS-LIKE 19) & Brapa_ESTC044364 & 16772 & 15569 & 1.1 & 0.9 \\
\hline & & & Brapa_ESTC018998 & 12476 & 12321 & 1.0 & 1.0 \\
\hline & AT3G12810 & PIE1 (PHOTOPERIOD-INDEPENDENT EARLY FLOWERING 1) & Brapa_ESTC042862 & 16091 & 12137 & 1.3 & 0.8 \\
\hline & & & Brapa_ESTC024641 & 14327 & 8484 & 1.7 & 0.6 \\
\hline & AT2G06210 & ELF8 (EARLY FLOWERING 8) & Brapa_ESTC004485 & 15388 & 12464 & 1.2 & 0.8 \\
\hline & & & Brapa_ESTC042284 & 12694 & 10565 & 1.2 & 0.8 \\
\hline & AT1G07050 & CONSTANS-like protein-related & Brapa_ESTC021115 & 15190 & 10154 & 1.5 & 0.7 \\
\hline & AT1G77080 & AGL27, MAF1 (MADS AFFECTING FLOWERING 1) & Brapa_ESTC000396 & 14927 & 10695 & 1.4 & 0.7 \\
\hline & AT3G07650 & COL9 (CONSTANS-LIKE 9) & Brapa_ESTC042798 & 14472 & 8979 & 1.6 & 0.6 \\
\hline & & & Brapa_ESTC051649 & 12413 & 8766 & 1.4 & 0.7 \\
\hline & & & Brapa_ESTC021535 & 12256 & 7067 & 1.7 & 0.6 \\
\hline & & & Brapa_ESTC025316 & 8692 & 4979 & 1.7 & 0.6 \\
\hline & & & Brapa_ESTC049114 & 7570 & 5204 & 1.5 & 0.7 \\
\hline & & & Brapa_ESTC049113 & 7031 & 5176 & 1.4 & 0.7 \\
\hline & & & Brapa_ESTC006144 & 6478 & 9542 & 0.7 & 1.5 \\
\hline & AT4G28190 & ULT1 (ULTRAPETALA1) & Brapa_ESTC044575 & 14100 & 11058 & 1.3 & 0.8 \\
\hline & AT1G79730 & ELF7 (EARLY FLOWERING 7) & Brapa_ESTC006396 & 12278 & 10830 & 1.1 & 0.9 \\
\hline & & & Brapa_ESTC009946 & 8400 & 10613 & 0.8 & 1.3 \\
\hline & AT4G36920 & AP2 (APETALA 2) & Brapa_ESTC034160 & 10951 & 9936 & 1.1 & 0.9 \\
\hline & & & Brapa_ESTC007967 & 7301 & 8061 & 0.9 & 1.1 \\
\hline & & & Brapa_ESTC012323 & 4120 & 5899 & 0.7 & 1.4 \\
\hline & & & Brapa_ESTC013840 & 3821 & 4959 & 0.8 & 1.3 \\
\hline & & & Brapa_ESTC023600 & 2272 & 1607 & 1.4 & 0.7 \\
\hline & AT3G04610 & FLK (FLOWERING LOCUS KH DOMAIN) & Brapa_ESTC021699 & 10239 & 6514 & 1.6 & 0.6 \\
\hline & & & Brapa_ESTC015151 & 8990 & 9444 & 1.0 & 1.1 \\
\hline & AT2G45660 & SOC1/AGL20 (AGAMOUS-LIKE 20)(SOC1-3) & Brapa_ESTC034801 & 9787 & 7499 & 1.3 & 0.8 \\
\hline & AT2G40080 & ELF4 (EARLY FLOWERING 4) & Brapa_ESTC038745 & 9602 & 6902 & 1.4 & 0.7 \\
\hline & & & Brapa_ESTC023094 & 8429 & 13088 & 0.6 & 1.6 \\
\hline & & & Brapa_ESTC027935 & 6642 & 4190 & 1.6 & 0.6 \\
\hline & AT5G15850 & COL1 (CONSTANS-LIKE 1) & Brapa_ESTC013309 & 9416 & 16434 & 0.6 & 1.7 \\
\hline
\end{tabular}


showed paralog-specific pattern: i.e., BrFLC1 (Bra009055; Brapa_ESTC016533) and BrFLC2 (Bra028599; Brapa ESTC012276) in Chiifu, BrFLCL/BrFLC5 (FLC-Like, Bra022771; Brapa_ESTC017216 and Brapa_ESTC027067) in RCBr, and BrFLC3 (Bra006051; Brapa_ESTC013303 and Brapa_ESTC021830) in both plants. CONSTNASLIKE 9 (COL9) was also paralog specific expression: Brapa_ESTC027877 (Bra029666; BrCOL9-2) and Brapa ESTC051650 (Bra001264; BrCOL9-3) for up-regulated ones in $\mathrm{RCBr}$, but rest (most of them are BrCOL9-1; Bra040020) in both plants. These paralog-specific expressions of flowering genes were highlight of this study.

\section{Gibberellin metabolism-related genes}

Since gibberellins (GAs) control flowering in concert with cytokinin (Matías-Hernández et al. 2016), the expression of GA-metabolism-related genes were examined (Table 4). Most genes involved in increase of the GA activity were up-regulated in RCBr; GA3OX1/GA4 (GA requiring 4) and $G A 20 O X 3$ (Gibberellin 20 oxidase 3). Only GA2OX2 (Gibberelin 2-beta-dioxygenase) expression was high in Chiifu, but its function has not been identified besides its involvement in GA catabolism.

\section{Confirmation of selected gene expression}

Fig. 2 showed genes whose expression was decreased during the development of $\mathrm{RCBr}$, while increased in Chiifu. These included MADS AFFECTING FLOWERING 4 (FCL4/MAF4), FLC2, FLOWERING LOCUS D (FLD), REDUCED VERNALIZATION RESPONSE 1 (VRNI), REDUCED VERNALIZATION RESPONSE 2 (VRN2, Polycomb group), METHYL-CPG-BINDING DOMAIN 9 $(M B D 9)$ and KNAT5. Most of them are known to be floral repressors. The expression of these genes was gradually increased in Chiifu even though this period belongs to be very early developmental stages.

Photoperiod is important for controlling flowering of Brassica species. To elucidate its association, several TF genes and flowering-related genes were selected and their expressions were examined during a day under LD and SD conditions. Plants grown for 21 DAG under LD and SD were sampled at indicated time (Fig. 3A). B. rapa

Table 4. Genes related to gibberellic acid metabolism.

\begin{tabular}{|c|c|c|c|c|c|c|}
\hline \multirow{2}{*}{ At_Locus } & \multirow{2}{*}{ Gene annotation } & \multirow{2}{*}{ Br_SEQ_ID } & \multicolumn{2}{|c|}{ Prove intensity } & \multicolumn{2}{|c|}{ Fold change } \\
\hline & & & $\mathrm{RCBr}$ & Chiifu & $\mathrm{R} / \mathrm{C}^{\mathrm{z})}$ & $\mathrm{C} / \mathrm{R}$ \\
\hline \multirow[t]{2}{*}{ AT1G30040 } & GA2OX2 (Gibberellin 2-beta-dioxygenase) & Brapa_ESTC040202 & 1319 & 6104 & 0.2 & 4.6 \\
\hline & & Brapa_ESTC015031 & 16 & 1969 & 0.0 & 126.4 \\
\hline AT1G02400 & GA2OX6/DTA1 (Gibberellin 2-OXIDASE 6) & Brapa_ESTC015242 & 10762 & 8386 & 1.3 & 0.8 \\
\hline \multirow[t]{2}{*}{ AT4G21200 } & GA2OX8 (Gibberellin 2-OXIDASE 8) & Brapa_ESTC024684 & 431 & 665 & 0.6 & 1.5 \\
\hline & & Brapa_ESTC015062 & 423 & 624 & 0.7 & 1.5 \\
\hline AT1G15550 & GA3OX1/GA4 (GA REQUIRING 4) & Brapa_ESTC027719 & 554 & 164 & 3.4 & 0.3 \\
\hline \multirow[t]{3}{*}{ AT5G07200 } & GA20OX3/YAP169 (Gibberellin 20 oxidase 3) & Brapa_ESTC045377 & 1296 & 155 & 8.4 & 0.1 \\
\hline & & Brapa_ESTC029845 & 4761 & 183 & 26.1 & 0.0 \\
\hline & & Brapa_ESTC027440 & 1114 & 81 & 13.7 & 0.1 \\
\hline \multirow[t]{6}{*}{ AT5G14920 } & Gibberellin-regulated family protein & Brapa_ESTC003065 & 9782 & 9954 & 1.0 & 1.0 \\
\hline & & Brapa_ESTC016390 & 5777 & 9747 & 0.6 & 1.7 \\
\hline & & Brapa_ESTC042364 & 10773 & 8665 & 1.2 & 0.8 \\
\hline & & Brapa_ESTC024407 & 6879 & 6685 & 1.0 & 1.0 \\
\hline & & Brapa_ESTC007229 & 5209 & 4283 & 1.2 & 0.8 \\
\hline & & Brapa_ESTC010071 & 5161 & 3227 & 1.6 & 0.6 \\
\hline AT5G59845 & Gibberellin-regulated family protein & Brapa_ESTC007822 & 507 & 20 & 25.9 & 0.0 \\
\hline \multirow[t]{2}{*}{ AT1G74670 } & Gibberellin-responsive protein, putative & Brapa_ESTC037994 & 4417 & 3177 & 1.4 & 0.7 \\
\hline & & Brapa_ESTC008005 & 3581 & 2190 & 1.6 & 0.6 \\
\hline AT1G22690 & Gibberellin-responsive protein, putative & Brapa_ESTC003796 & 5081 & 1538 & 3.3 & 0.3 \\
\hline AT5G51310 & Gibberellin 20-oxidase-related & Brapa_ESTC046793 & 859 & 1135 & 0.8 & 1.3 \\
\hline AT3G10185 & Gibberellin-regulated GASA/GAST/Snakin family protein & Brapa_ESTC036747 & 4237 & 5060 & 0.8 & 1.2 \\
\hline AT4G26420 & GAMT1 | Gibberellin carboxyl-O-methyltransferase & Brapa_ESTC019836 & 1067 & 287 & 3.7 & 0.3 \\
\hline AT5G56300 & GAMT2 | Gibberellin carboxyl-O-methyltransferase & Brapa_ESTC009976 & 773 & 115 & 6.7 & 0.1 \\
\hline
\end{tabular}

${ }^{\mathrm{z})} \mathrm{R} / \mathrm{C}$ and $\mathrm{C} / \mathrm{R}$ indicate the expression ratio in $\mathrm{RCBr}$ over Chiifu and Chiifu over $\mathrm{RCBr}$, respectively. 


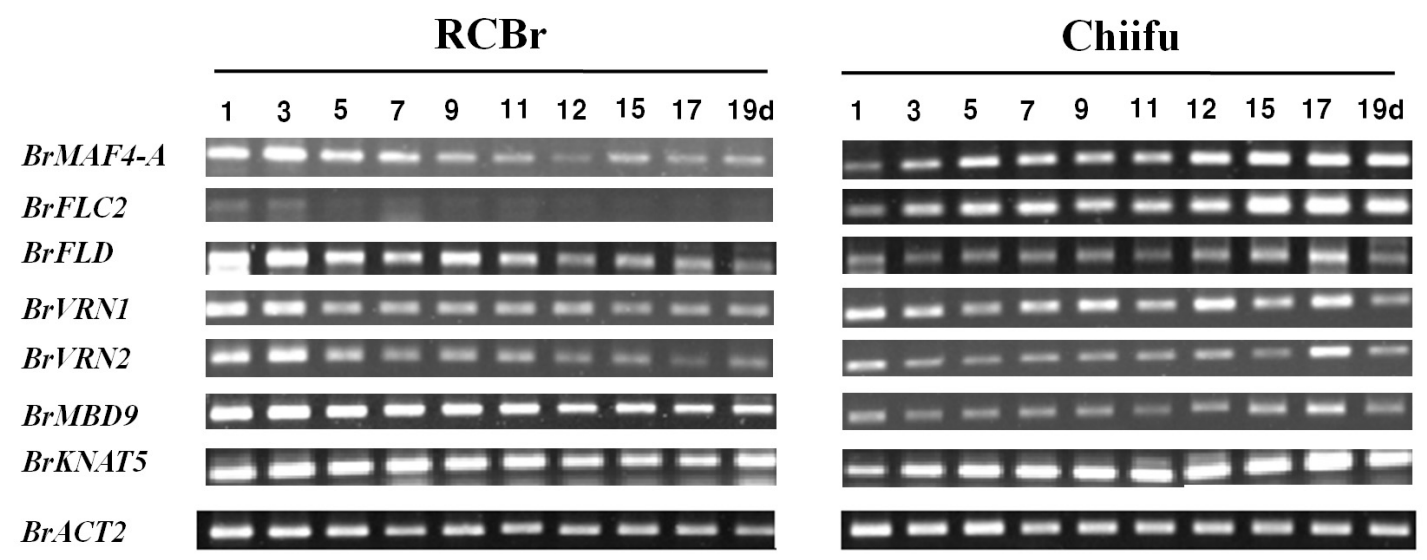

Fig. 2. Genes whose expression was decreased in $\mathrm{RCBr}$, while increased in Chiifu. $\mathrm{RCBr}$ and Chiifu were grown in long-day condition condition for 19 days and shoot was sampled at 4th hour of light period.

A

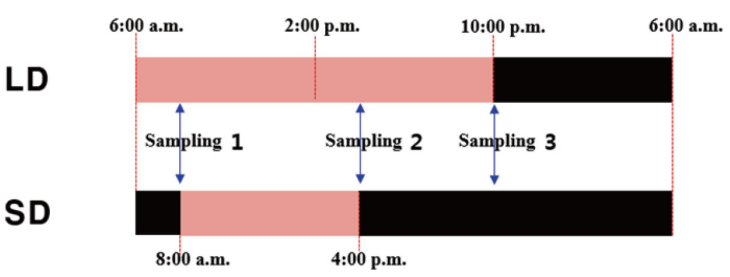

B

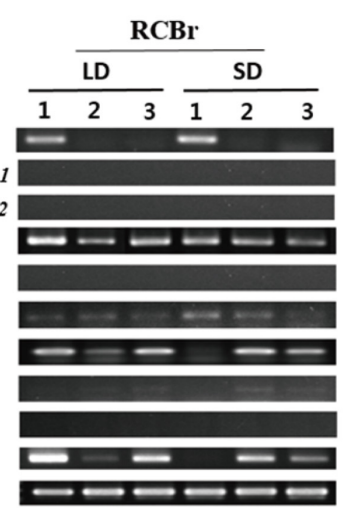

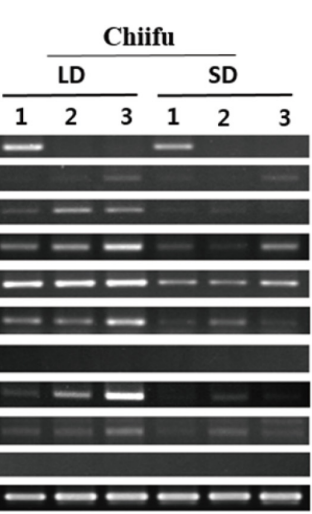

C

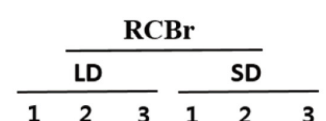

BrCCA1

$\mathrm{BrCO}$

BrCOL1-1

BrCOL1-2

BrCOL2-1

BrCOL2-2

$\mathrm{BrCOL3}$

BrCOL9-1

BrCOL9-2

BrCOL9-3

BrACT2

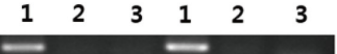

$$
=
$$
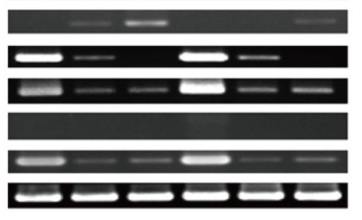

$-=-$

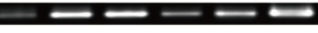

$-=-$

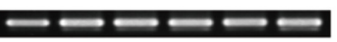
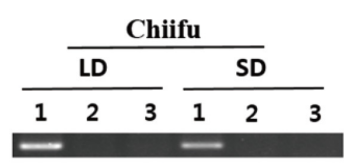

$=$

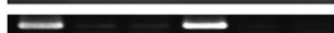

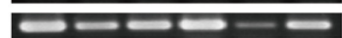

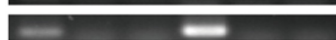

$\longrightarrow$

$-2=$

든

$=$

-

$\longrightarrow \longrightarrow$

Fig. 3. Expression of flowering- and photoperiod pathway-related genes. (A) Photoperiod for plant growth and sampling time a day. (B) Genes showing differential expression in a microarray. (C) Constance (CO) and its paralogs. BrCCA1 was used as control for circadian rhythm.

LD: long-day condition, SD: short-day condition.

\section{CIRCADIAN CLOCK ASSOCIATED 1 (BrCCA1) was} used as a control for the circadian clock. The expression of $B r F L C 2$ was high in Chiifu, but not detected in RCBr. Individual paralogues of BrSEP1 (SEPALLATA1/AGL2) were specific for either plant (Fig. 3B). However, photoperiodic pathway integrator, $\mathrm{CO}$ and its relatives (COLs) were expressed with similar patterns in both plants
(Fig. 3C). Only BrCOL2-1 was expressed in Chiifu. Taken together, there was no photoperiodic- dependent expression, but the expression of $B r F L C 2, B r S E P 1 s$ and BrCOL2-1 was plant-specific. These daily expression patterns was not agreement with microarray data, due to sampling time difference. 


\section{DISCUSSION}

Because of striking difference in periods required for flowering between $\mathrm{RCBr}$ and B. rapa ssp. pekinensis, inbred line Chiifu, normalization of developmental stages of these two plants would be almost impossible. Therefore, identification of master gene(s) for controlling flowering time would be also very difficult. However, microarray data in this study showed remarkable difference in the expression of flowering-related genes between two plants; high expression of flowering promoting genes in $\mathrm{RCBr}$, whereas high expression of floral repressor genes in Chiifu. DEGs between $\mathrm{RCBr}$ and Chiifu included many NHFs with respect to BlastN against Arabidopsis gene ID, suggesting that these would be Brassica species-specific genes. That can be supported by that most sequences were matched to the public genome data or NCBI data for $B$. napus and B. oleracea. For example, Brapa_ESTC051261 was the most highly expressed gene (937 fold) in Chiifu compared with RCBr. As result of BlastN in $\mathrm{RCBr}$, this clone was matched to $100 \%$ with B. napus uncharacterized LOC106444620, ncRNA and 90\% with B. oleracea var. oleracea uncharacterized LOC106327354. Brapa ESTC033111 was the most highly expressed gene (301 fold) in RCBr: $93 \%$ identical to B. napus uncharacterized LOC106448050 and $92 \%$ to B. oleracea var. oleracea uncharacterized LOC106330763. This finding strongly suggests that functional study on these Brassica-specific genes will be very important for understanding evolution of Brassicaceae crops.

\section{Analysis of DEGs}

GO enrichment analysis with DEGs showed distinct difference between $\mathrm{RCBr}$, very early flowering phenotype, and Chiifu, a slow or late flowering phenotype (Fig. 1). Flowering process-related genes were specifically induced in $\mathrm{RCBr}$, whereas temperature and other environment stress tolerant-related genes were expressed in Chiifu. Some general biological processes were conserved in both $\mathrm{RCBr}$ and Chiifu. This result might imply that Chiifu is not ready to flower yet. However, it was ruled out whether this difference is due to the difference in developmental stages during whole life cycle.

\section{Expression of TF genes}

TFs control the expression of a large number genes, thereby exerting big impact on plant morphogenesis. As shown in Table 2, many TFs were highly expressed in both plants, some were specifically expressed in $\mathrm{RCBr}$ or in Chiifu. Based on current knowledge, it was hard to find out the specific association with growth and development for highly expressed TFs in both plants; i.e., RAP2.4, the most highly expressed gene, is known to promote leaf senescence (Xu et al. 2010). However, several genes among RCBr-induced TFs seemed to be closely related to early flowering phenotype. TCP family determines in the height of inflorescence shoot (Davière et al. 2014), which might be related to short height of RCBr. SHN2 is known to be related to flower organ (Shi et al. 2011), and CAULIFLOWER (CAL) is closely related to another MADS box gene APETALAl (APl) and control floral meristem development (Alvarez-Buylla et al. 2000).

Regarding to genes induced in Chiifu, most TFs appeared to be related to plant growth and development as follows. KNAT5 regulates photomorphogenic responses and represses late steps in gibberellin biosynthesis. (Hay et al. 2002). AP2 encoding a member of the ERF (ethylene response factor) subfamily B-3 of ERF/AP2 TF family may be related to the ethylene-singalling pathway. AtMYB34 regulates indole glucosinolate homeostasis (Celenza et al. 2005). ATHB6, a target of the protein phosphatase ABI1, regulates negatively ABA responses in Arabidopsis (Himmelbach et al. 2002). Only CLF, a repressor of AG function (Goodrich et al. 1997), is related to flowering; it suppresses flowering by inducing misexpression of floral promoting genes (Lopez-Vernaza et al. 2012)

\section{Expression of GA metabolism-related genes}

GA content is associated with fertility (Plackett et al. 2012). GA 20-oxidase (GA20ox) regulates GA content (Yamaguchi 2008), and there are five GA20ox genes in Arabidopsis, GA20ox1, GA20ox2, GA20ox3, GA20ox4, and GA20ox5 (Hedden et al. 2002). Among them, GA200x3 functions almost entirely redundantly with GA20ox1 and GA20ox2 at most developmental stages, including the floral transition, thereby these genes control 
floral organ growth and anther development (Plackett et al. 2012). In our results (Table 4), GA20OX3 was highly expressed in $\mathrm{RCBr}$, suggesting the possible function in flowering. In addition, several GA responsive genes were up-regulated in $\mathrm{RCBr}$, but their role in flowering have to be solved. Only one gene, GA2OX2 (Gibberellin 2-beta-dioxygenase) was up-regulated in Chiifu, but the function of this gene has not been identified yet.

\section{Expression of flowering-related genes}

Regarding to flowering-related genes, several flowering-promoting genes, such as PISTILLATA (PI), SEP1 and $A P 1$, were up-regulated in $\mathrm{RCBr}$, whereas floral repressors, such FLC and MAF4, were up-regulated in Chiifu (Table 3 ). These results can partially support why these two plants exhibit contrasting flowering phenotypes, rapid vs. slow. Interestingly, several genes contain paralogues; FLC, COL9 and SOC1. Schranz et al. (2002) and Franks et al. (2015) reported presence of four FLC paralogues in $B$. rapa (BrFLC1, BrFLC2, BrFLC3, and BrFLC5). A genetic-genomics approach revealed that BrFLC2 is a major regulator of flowering time in B. rapa (Wu et al. 2012; Xiao et al. 2013; 2014). Recently, Li et al. (2016) reported that early flowering phenotypes of $B$. rapa is related to be nonfunctional $B r F L C$ s which are truncated form by premature termination, but slow or late flowering types contain functional or intact forms of $B r F L C 1$, BrFLC2, and BrFLC3. In addition, Song et al. (2015) found out that expression of only one or some of paralogues is closely related to photoperiodic flowering in B. rapa. All these facts might be similar to our study: i.e., $B r F L C 2$ were up-regulated in Chiifu, a slow or late flowering phenotype. However, BrFLC5 was up-regulated in $\mathrm{RCBr}$, suggesting the another possible role of FLC besides flowering control.

RT-PCR results of selected genes demonstrated that the expression of flowering repressor genes was gradually decreased in $\mathrm{RCBr}$, while gradually increased in Chiifu (Fig. 2). These included BrMBD9, BrVRN1, BrVRN2, $B r F L C$, and $B r F L D$. MBD9 controls flowering time by modulating gene expression through DNA methylation and histone acetylation (Yaish et al. 2009). VRN1 and VRN2 affect vernalization response of late flowering plants (Chandler et al. 1996). FLD (Flowering Locus D) encodes a plant ortholog of the human Lys-Specific Demethylase 1 (LSD1) protein. FLD functions in histone $\mathrm{H} 3 \mathrm{~K} 4$ demethylation and $\mathrm{H} 3 / \mathrm{H} 4$ deacetylation to repress the expression of FLC (Jiang et al. 2007; Yu et al. 2011). Our data well agree with previous findings.

It was expected that photoperiodic flowering signalingrelated genes are differentially expressed between $\mathrm{RCBr}$ and Chiifu, but no significant difference was observed (Fig. 3). Special attention paid to COL9 (CONSTNAS-LIKE 9) which delays flowering by down-regulation of expression of CO, FT, and SOC1 (Cheng and Wang 2005). However, three paralogues showed similar expression patterns between two plants.

\section{ACKNOWLEDGEMENTS}

This work was supported by Research Fund of Chungnam National University (CNU), Daejeon, Korea, to Yoonkang Hur (2015-1115-01).

\section{REFERENCES}

Alvarez-Buylla ER, Pelaz S, Liljegren SJ, Gold SE, Burgeff C, Ditta GS, et al. 2000. An ancestral MADS-box gene duplication occurred before the divergence of plants and animals. Proc. Natl. Acad. Sci. U.S.A. 10: 5328-5333.

Ashburner M, Ball CA, Blake JA, Botstein D, Butler H, Cherry JM, et al; The Gene Ontology Consortium. 2000. Gene ontology: tool for the unification of biology. Nat. Genet. 25: 25-29.

Celenza JL, Quiel JA, Smolen GA, Merrikh H, Silvestro AR, Normanly J, et al. 2005. The Arabidopsis ATR1 Myb transcription factor controls indolic glucosinolate homeostasis. Plant Physiol. 137: 253-262.

Chandler J, Wilson A, Dean C. 1996. Arabidopsis mutants showing an altered response to vernalization. Plant J. 10: 637-644.

Cheng XF, Wang ZY. 2005. Overexpression of COL9, a CONSTANS-LIKE gene, delays flowering by reducing expression of $C O$ and $F T$ in Arabidopsis thaliana. Plant J. 43: 758-768.

Davière JM, Wild M, Regnault T, Baumberger N, Eisler H, 
Genschik P, et al. 2014. Class I TCP-DELLAR interactions in inflorescence shoot apex determine plant height. Curr. Biol. 24: 1923-1928.

Devisetty UK, Covington MF, Tat AV, Lekkala S, Maloof JN. 2014. Polymorphism identification and improved genome annotation of Brassica rapa through deep RNA sequencing. G3 (Bethesda) 4: 2065-2078.

Dong X, Feng H, Xu M, Lee J, Kim YK, Lim YP, et al. 2013. Comprehensive analysis of genic male sterility-related genes in Brassica rapa using a newly developed $\mathrm{Br} 300 \mathrm{~K}$ oligomeric chip. PLoS One 8: e72178.

Du Z, Zhou X, Ling Y, Zhang Z, Su Z. 2010. agriGO: a GO analysis toolkit for the agricultural community. Nucleic Acids Res. 38: W64-70.

Franks SJ, Perez-Sweeney B, Strahl M, Nowogrodzki A, Weber JJ, Lalchan R, et al. 2015. Variation in the flowering time orthologs $\mathrm{BrFLC}$ and $\mathrm{BrSOCl}$ in a natural population of Brassica rapa. Peer J. 3: e1339.

Gómez-Campo C, Prakash S. 1999. Origin and domestication, p. 33-58. In: C. Gómez-Campo (ed.). Biology of Brassica coenospecies. Elsevier, Amsterdam.

Goodrich J, Puangsomlee P, Martin M, Long D, Meyerowitz EM, Coupland G. 1997. A Polycomb-group gene regulates homeotic gene expression in Arabidopsis. Nature 386: 44-51.

Hay A, Kaur H, Phillips A, Hedden P, Hake S, Tsiantis M. 2002. The gibberellin pathway mediates KNOTTED1type homeobox function in plants with different body plans. Curr. Biol. 12: 1557-1565.

Hedden P, Phillips AL, Rojas MC, Carrera E, Tudzynski B. 2001. Gibberellin biosynthesis in plants and fungi: a case of convergent evolution? J. Plant Growth Regul. 20: 319-331.

Helliwell CA, Anderssen RS, Robertson M, Finnegan EJ. 2015. How is FLC repression initiated by cold? Trends Plant Sci. 20: 76-82.

Helliwell CA, Wood CC, Robertson M, James Peacock W, Dennis ES. 2006. The Arabidopsis FLC protein interacts directly in vivo with SOC1 and FT chromatin and is part of a high-molecular-weight protein complex. Plant J. 46: 183-192.

Himmelbach A, Hoffmann T, Leube M, Höhener B, Grill E. 2002. Homeodomain protein ATHB6 is a target of the protein phosphatase $\mathrm{ABI} 1$ and regulates hormone responses in Arabidopsis. EMBO J. 21: 3029-3038.
Jiang D, Yang W, He Y, Amasino RM. 2007. Arabidopsis relatives of the human lysine-specific demethylase 1 repress the expression of FWA and FLOWERING LOCUS $C$ and thus promote the floral transition. Plant Cell 19: 2975-2987.

Kakizaki T, Kato T, Fukino N, Ishida M, Hatakeyama K, Matsumoto S. 2011. Identification of quantitative trait loci controlling late bolting in Chinese cabbage (Brassica rapa L.) parental like Nou 6 gou. Breed. Sci. 61: 151-159.

Kanehisa M, Araki M, Goto S, Hattori M, Hirakawa M, Itoh $\mathrm{M}$, et al. 2008. KEGG for linking genomes to life and the environment. Nucleic Acids Res. 36: D480-484.

Kim JS, Chung TY, King GJ, Jin M, Yang TJ, Jin YM, et al. 2006. A sequence-tagged linkage map of Brassica rapa. Genetics 174: 29-39.

Kim SY, Park BS, Kwon SJ, Kim J, Lim MH, Park YD, et al. 2007. Delayed flowering time in Arabidopsis and Brassica rapa by the overexpression of FLOWERING LOCUS $C$ (FLC) homologs isolated from Chinese cabbage (Brassica rapa L.: ssp. pekinensis). Plant Cell Rep. 26: 327-336.

Lee H, Suh SS, Park E, Cho E, Ahn JH, Kim SG, et al. 2000. The AGAMOUS-LIKE 20 MADS domain protein integrates floral inductive pathways in Arabidopsis. Genes Dev. 14: 2366-2376.

Li X, Zhang S, Bai J, He Y. 2016. Tuning growth cycles of Brassica crops via natural antisense transcripts of $B r F L C$. Plant Biotechnol. J. 14: 905-914.

Lin SI, Wang JG, Poon SY, Su CL, Wang SS, Chiou TJ. 2005. Differential regulation of FLOWERING LOCUS C expression by vernalization in cabbage and Arabidopsis. Plant Physiol. 137: 1037-1048.

Lopez-Vernaza M, Yang S, Müller R, Thorpe F, de Leau E, Goodrich J. 2012. Antagonistic roles of SEPALLATA3, $F T$ and $F L C$ genes as targets of the polycomb group gene CURLY LEAF. PLoS One 7: e30715.

Mao F, Wu F, Yu X, Bai J, Zhong W, He Y. 2014. MicroRNA319a-targeted Brassica rapa ssp. pekinensis TCP genes modulate head shape in Chinese cabbage by differential cell division arrest in leaf regions. Plant Physiol. 164: 710-720.

Matías-Hernández L, Aguilar-Jaramillo AE, Cigliano RA, Sanseverino W, Pelaz S. 2016. Flowering and trichome development share hormonal and transcription factor regulation. J. Exp. Bot. 67: 1209-1219. 
Musgrave ME. 2000. Realizing the potential of rapid-cycling Brassica as a model system for use in plant biology research. J. Plant Growth Regul. 19: 314-325.

Plackett AR, Powers SJ, Fernandez-Garcia N, Urbanova T, Takebayashi Y, Seo M, et al. 2012. Analysis of the developmental roles of the Arabidopsis gibberellin 20-oxidases demonstrates that GA20oxl, -2, and -3 are the dominant paralogs. Plant Cell 24: 941-960.

Putterill J, Robson F, Lee K, Simon R, Coupland G. 1995. The CONSTANS gene of Arabidopsis promotes flowering and encodes a protein showing similarities to zinc finger transcription factors. Cell 80: 847-857.

Samach A, Onouchi H, Gold SE, Ditta GS, Schwarz-Sommer Z, Yanofsky MF, et al. 2000. Distinct roles of CONSTANS target genes in reproductive development of Arabidopsis. Science 288: 1613-1616.

Schranz ME, Quijada P, Sung SB, Lukens L, Amasino R, Osborn TC. 2002. Characterization and effects of the replicated flowering time gene $F L C$ in Brassica rapa. Genetics 162: 1457-1468.

Shi JX, Malitsky S, De Oliveira S, Branigan C, Franke RB, Schreiber L, et al. 2011. SHINE transcription factors act redundantly to pattern the archetypal surface of Arabidopsis flower organs. PLoS Genet. 7: e1001388.

Song X, Duan W, Huang Z, Liu G, Wu P, Liu T, et al. 2015. Comprehensive analysis of the flowering genes in Chinese cabbage and examination of evolutionary pattern of CO-like genes in plant kingdom. Sci. Rep. 5: 14631.

Takada S, Goto K. 2003. Terminal flower2, an Arabidopsis homolog of heterochromatin protein1, counteracts the activation of floweringlocus $\mathrm{T}$ by constans in the vascular tissues of leaves to regulate flowering time. Plant Cell 15: 2856-2865.

Wang X, Wang H, Wang J, Sun R, Wu J, Liu S, et al. 2011.
The genome of the mesopolyploid crop species Brassica rapa. Nat. Genet. 43: 1035-1039.

Wang Y, Wu F, Bai J, He Y. 2014. BrpSPL9 (Brassica rapa ssp. pekinensis SPL9) controls the earliness of heading time in Chinese cabbage. Plant Biotechnol. J. 12: 312-321.

Williams PH, Hill CB. 1986. Rapid-cycling populations of brassica. Science 232: 1385-1389.

Wu J, Wei K, Cheng F, Li S, Wang Q, Zhao J, et al. 2012. A naturally occurring InDel variation in BraA.FLC.b $(B r F L C 2)$ associated with flowering time variation in Brassica rapa. BMC Plant Biol. 12: 151.

Xiao D, Wang H, Basnet RK, Zhao J, Lin K, Hou X, et al. 2014. Genetic dissection of leaf development in Brassica rapa using genetical genomics approach. Plant Physiol. 164: 1309-1325.

Xiao D, Zhao JJ, Hou XL, Basnet RK, Carpio DPD, Zhang NW, et al. 2013. The Brassica rapa FLC homologue $F L C 2$ is a key regulatory of flowering time, identified through transcriptional co-expression networks. J. Exp. Bot. 64: 4503-4516.

Xu H, Wang X, Chen J. 2010. Overexpression of the Rap2.4f transcriptional factor in Arabidopsis promotes leaf senescence. Sci. China Life Sci. 53: 1221-1226.

Yaish MW, Peng M, Rothstein SJ. 2009. AtMBD9 modulates Arabidopsis development through the dual epigenetic pathways of DNA methylation and histone acetylation. Plant J. 59: 123-135.

Yamaguchi S. 2008. Gibberellin metabolism and its regulation. Annu. Rev. Plant Biol. 59: 225-251.

Yu CW, Liu X, Luo M, Chen C, Lin X, Tian G, et al. 2011. HISTONE DEACETYLASE 6 interacts with FLOWERING LOCUS D and regulates flowering in Arabidopsis. Plant Physiol. 156: 173-184. 